\title{
Reducing Multidimensional Poverty and Destitution: Pace and Patterns
}

\section{Sabina Alkire and Ana Vaz | June 2014}

This briefing examines how multidimensional poverty changed in 34 countries covering 2.5 billion people. It documents trends in poverty and destitution across and within these countries, and according to different kinds of deprivation. It provides some rich results which we hope will spark others to look deeper into specific country examples, so that together we can provide some insightful stories, identify bottlenecks to progress and fuel realistic hope about what is possible.

\section{WHICH COUNTRIES DID WE STUDY AND HOW?}

We report changes over time in Global MPI and its components the headcount ratio $(\mathbf{H})$, (the percentage of people identified as multidimensionally poor), and intensity (A), (the average percentage of deprivations the poor people experience together), as well as for the ten poverty indicators that are used to construct the index.

We do this for $\mathbf{3 4}$ countries and $\mathbf{3 3 8}$ subnational regions: Armenia, Bangladesh, Benin, Bolivia, Cambodia, Cameroon, Colombia, Dominican Republic, Egypt, Ethiopia, Gabon, Ghana, Guyana, Haiti, India, Indonesia, Jordan, Kenya,
Lesotho, Madagascar, Malawi, Mozambique, Namibia, Nepal, Niger, Nigeria, Pakistan, Peru, Rwanda, Senegal, Tanzania, Uganda, Zambia and Zimbabwe.

We also report changes in destitution and inequality among the poor, and analyse disparities in trends across sub-national regions, and in some cases between ethnic groups. We zoom in to see which of the $10 \mathrm{MPI}$ indicators drove progress, and look at where population growth competes with or erases it. We also compare reductions in multidimensional poverty with trends in income poverty and economic growth.

\section{Key Findings}

- Of 34 countries having data on MPI poverty over time, 30 countries reduced multidimensional poverty (MPI), and the incidence of MPI $(\mathrm{H})$ significantly, and 24 reduced intensity (A) significantly

- When population growth is taken into account, 20 countries reduced the number of poor people across periods

- Nepal, Rwanda, Ghana and Tanzania had the largest absolute reductions in MPI poverty, followed by Bangladesh, Cambodia and Bolivia. Armenia, the Dominican Republic, Bolivia, Egypt, Peru and Colombia had strong reductions relative to their initial poverty levels, which were lower than the others

- Eight of the top ten countries in terms of absolute annualized rates of MPI reduction were Low Income or Least Developed Countries

- Absolute reductions in the intensity of MPI poverty were strongest in Rwanda, Ethiopia, Nepal, Bolivia, Niger, Tanzania, Cambodia, and Ghana

- Overall, 208 out of 338 subnational regions reduced MPI statistically significantly
- Ten countries reduced all MPI indicators significantly: Bolivia, Cambodia, Colombia, the Dominican Republic, Gabon, India, Indonesia, Mozambique, Nepal, and Rwanda; seven countries reduced 9 MPI indicators significantly, and six countries reduced $8 \mathrm{MPI}$ indicators significantly

- 32 countries reduced the censored headcount in sanitation statistically significantly; 28 or more countries reduced deprivations in assets, and cooking fuel significantly ${ }^{8}$

- In eight countries out of the 31 countries having subnational decompositions, every subnational region reduced MPI significantly

- Around half of the countries for which we have income data for a similar period reduced multidimensional poverty faster than income poverty. Bolivia, Ghana, and Rwanda cut MPI poverty two to three times faster than income poverty. Nepal made stellar progress in both

- The top-performing countries reduced both the headcount of MPI poverty and the intensity of poverty 
The 34 countries in our study come from every geographic region in the developing world, and between them house more than 2.5 billion people - just over one-third of the world's population (as per population estimates for 2010). They are Low, Lower Middle, and Upper Middle Income Countries, with a GNI per capita ranging from $\$ 320$ in Malawi to $\$ 10,040$ in Gabon. For three countries - Bangladesh 2004-2011, Ethiopia 2000-2011, and Peru 2005-2012 - we have comparisons across three data points or two periods.

To assess change we created rigorously comparable MPI values - which are denoted $\mathrm{MPI}_{\mathrm{T}}$ because some differ slightly from published MPI values. ${ }^{2}$ For details and an explanation of the constraints our study operates under, as well as the data in full, see Alkire, Roche and Vaz (2014) and visit our website www. ophi.org.uk. ${ }^{3}$

\section{HOW DID THEY PERFORM? - ABSOLUTE REDUCTIONS}

Of the 34 countries, 30 - covering $98 \%$ of the poor people across all 34 - had statistically significant reductions in multidimensional poverty. ${ }^{4} \mathbf{~ N e p a l}$ and Rwanda, our stars from last year, still led the 30 countries with their outstanding absolute decrease in MPI, followed by Ghana, Tanzania, Uganda, Bangladesh, Cambodia and Bolivia.

Strikingly, the countries that reduced MPI most in absolute terms were predominantly Low Income Countries (LICs) and Least Developed Countries (LDCs); in 2012, Nepal's GNI per capita was $\$ 700$; Rwanda's was $\$ 600$; Cambodia’s $\$ 880$; Tanzania’s \$570; and Bangladesh's \$840. All are Low Income Countries, with Cambodia's pace of growth being the fastest at over $6 \%$ during the survey period.

Nepal had the fastest progress in absolute terms, showing a fall in MPI from 0.350 to 0.217 - about -0.027 per year - and a fall in incidence $(\mathrm{H})$ from $65 \%$ to $44 \%$ in a five-year period (20062011). That is, $\mathrm{H}$ fell by 4.1 percentage points each year.

Rwanda and Ghana were close behind, reducing MPI by -0.026 and -0.021 on average every year, respectively, and reducing $\mathrm{H}$ by 3.4 percentage points per year. Elsewhere in Africa, Tanzania and Uganda also did very well, with an annualized MPI reduction of -0.018 and -0.015 , respectively. Tanzania reduced $\mathrm{H}$ by 2.3 percentage points per year, and Uganda by 2.2 percentage points.

\section{Absolute and Relative Change}

Absolute change: The reduction in poverty is calculated by subtracting one measure from another. For example, a 5 percentage point reduction of $\mathrm{H}$ could mean that $\mathrm{H}$ decreased from $75 \%$ to $70 \%$ or from $10 \%$ to $5 \%$. It's just the difference. To show the changes per year, the total change is divided by the number of years between the surveys. This makes it easier to compare countries if surveys are a different number of years apart.

Relative change: The relative rate of change is the difference in levels across two periods as a percentage of the initial period. The annualized relative rate of change is the compound rate of reduction per year between the initial and the final periods.
Bangladesh, Cambodia and Bolivia showed the next fastest reduction of MPI, reducing poverty rates between 2.5 and 3.2 percentage points respectively, and MPI by 0.017 per year.

A range of countries including Ethiopia, Mozambique, Haiti, Niger, Benin, Zambia, Nigeria, Lesotho, Kenya, Malawi, Zimbabwe, India, Gabon, and Cameroon had slower but still significant reductions in poverty. Four countries - Senegal, Jordan and Guyana - had no statistically significant reduction in poverty, and Madagascar had a statistically significant increase.

\section{HOW DID THEY PERFORM? - RELATIVE PROGRESS}

Absolute changes are easy to compare across countries, and are the key comparison to make. However, while a country with high poverty rates like Madagascar could reduce $\mathrm{H}$ by 10 percentage points, Colombia - with only $9 \%$ of people in poverty initially - could never do so. Poverty would be eradicated first! So we also look at compound annualized relative reductions, especially to understand the changes in poverty for countries with low absolute poverty levels.

Of our 34 countries, we found the biggest relative reductions in Armenia, the Dominican Republic and Bolivia; the latter cut poverty by a whopping $13 \%$ per year. Each of the top-performing countries - Nepal, Rwanda, Ghana, Tanzania, Cambodia and Bangladesh - slashed their original MPI by $5 \%$ to $9 \%$ per year - making them successes in both relative and absolute terms.

\section{REDUCTIONS IN HEADCOUNT VS REDUCTIONS IN INTENSITY}

Of the 34 countries for which we have data on MPI poverty over time, 30 countries reduced multidimensional poverty (MPI), and the incidence of MPI (H) significantly, and 24 reduced intensity (A) significantly.

Nearly all countries reduced incidence more than intensity. The exceptions were Ethiopia, where incidence fell by around 0.8 percentage points per year, while intensity fell by 1.0; and Niger, where incidence dropped 0.6 percentage points and intensity dropped 0.9.

The 'top performing' countries reduced both the incidence and the intensity of MPI poverty. Absolute reductions in intensity were strongest in Rwanda, Nepal, Ethiopia, Bolivia, Niger, Tanzania, Cambodia and Ghana, showing the important progress made in the poorest countries to reduce the share of hardships experienced by those who are poor.

\section{Breakdown by Indicator}

Ten countries reduced all MPI indicators significantly: Bolivia, Cambodia, Colombia, the Dominican Republic, Gabon, India, Indonesia ${ }^{5}$, Mozambique, Nepal, and Rwanda. Seven countries reduced 9 MPI indicators significantly, and six countries reduced $8 \mathrm{MPI}$ indicators significantly. Thus all indicators contributed to reductions in MPI.

Countries reduced MPI by tackling different indicators. Figure 3 shows how country profiles of reductions in poverty vary: Rwanda had the highest reductions in sanitation; Ghana in school attendance; Tanzania in child mortality as well as sanitation, and Uganda in water and assets. 


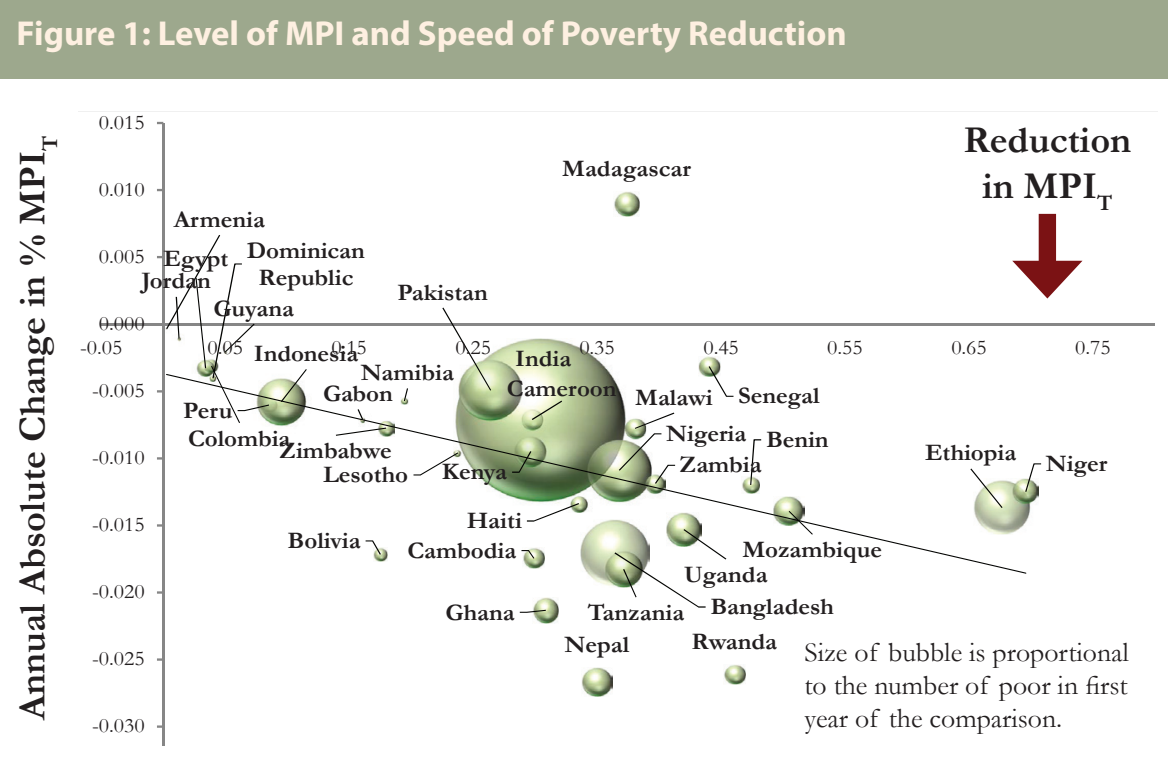

Multidimensional Poverty Index $\left(\mathrm{MPI}_{\mathrm{T}}\right)$ at initial year

Figure 2: MPI Reduction: Incidence and Intensity

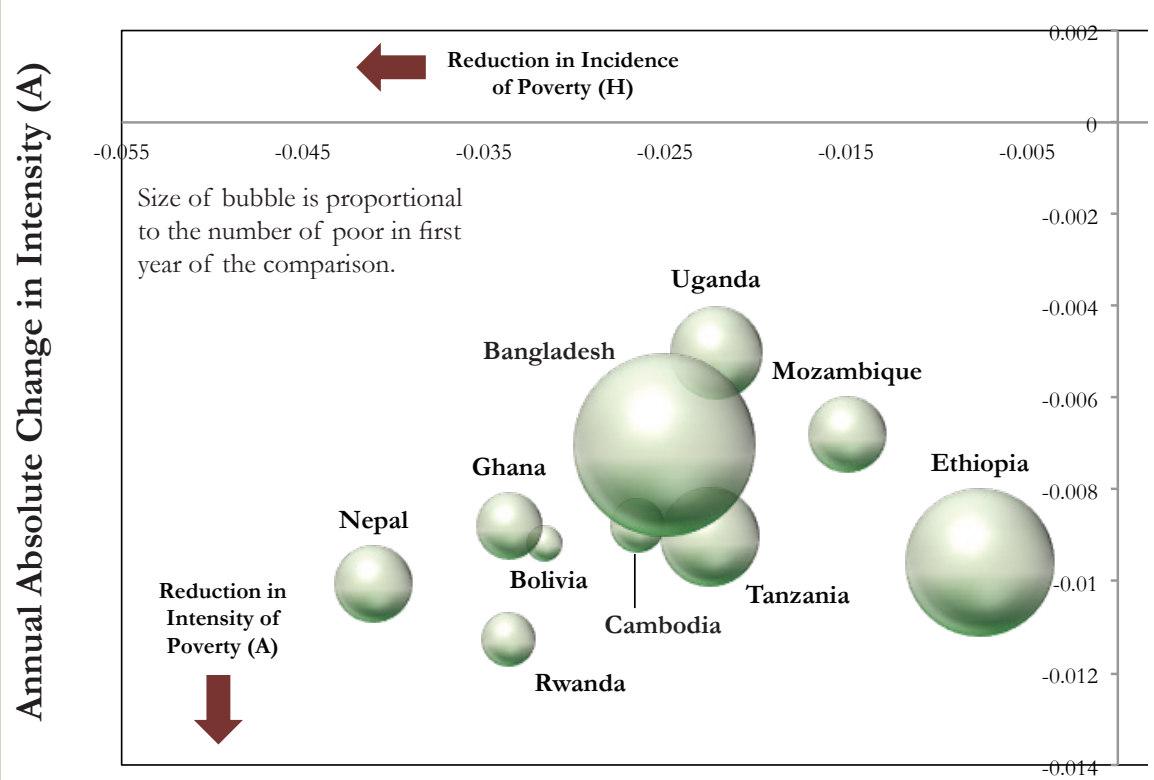

Annual Absolute Change in \% Headcount Ratio (H)

Figure 3: Absolute change in indicators

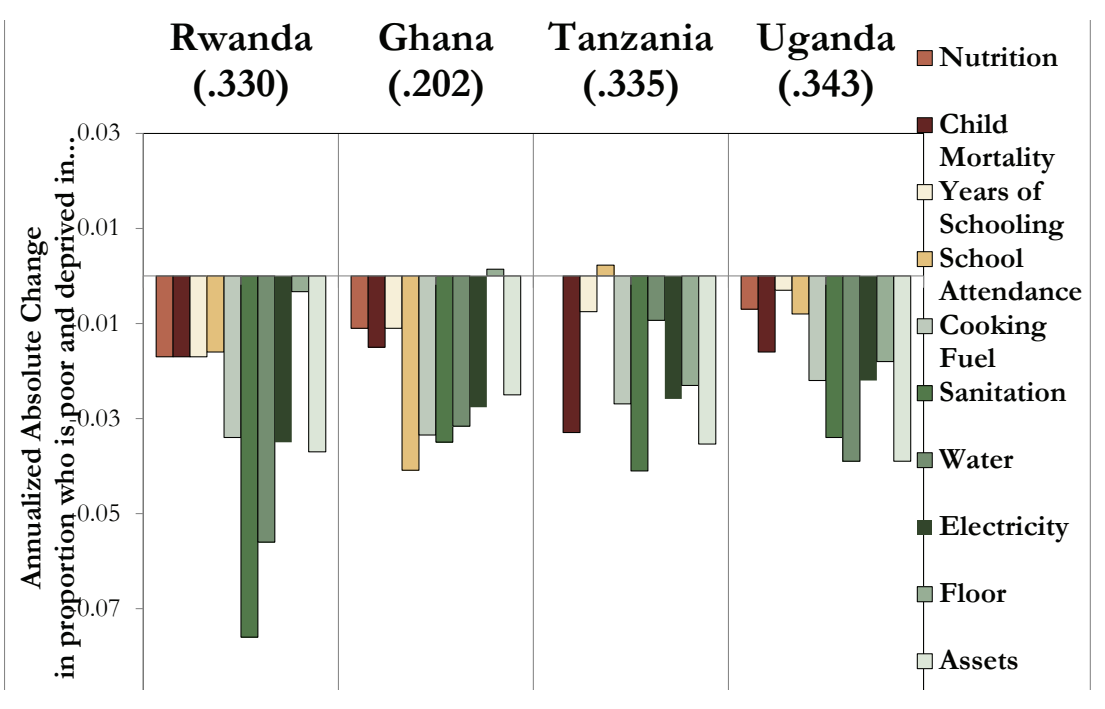

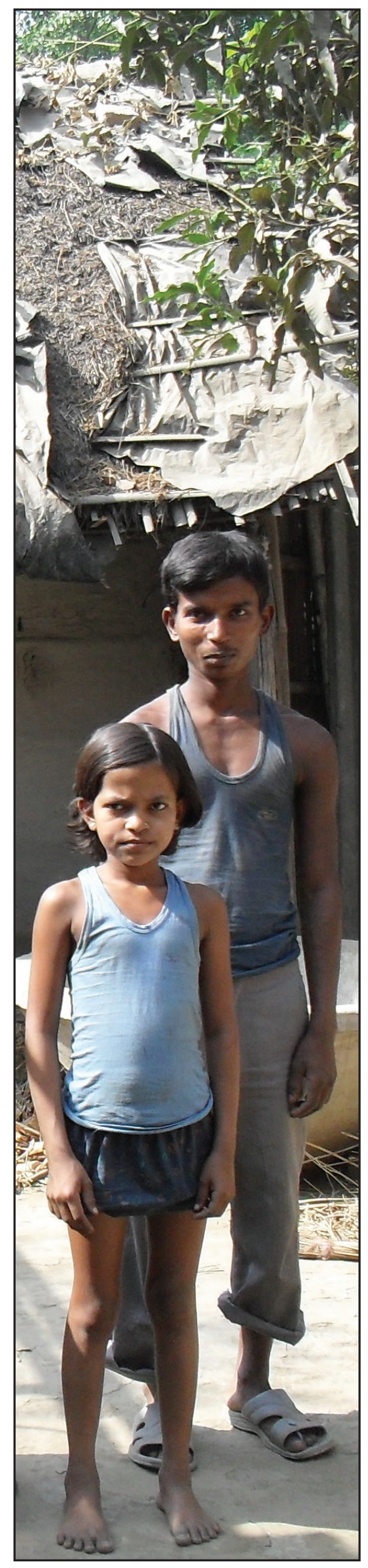


On average across all 34 countries, the fastest reductions were made by improving sanitation ( $2 \%$ per year on average). Strong reductions were also made in assets, flooring, electricity, water, and child mortality. There were slower reductions in the educational deprivations.

The changes varied according to location. We can analyse these by major geographic region, as well as by country and by each subnational region. Just at-a-glance: all regions registered the strongest improvements in sanitation; Africa had particularly strong changes in sanitation and water, assets and school attendance; in Latin America, assets, electricity and school attendance tended to change most; and South Asia made major gains in flooring, electricity, assets and nutrition.

\section{Disaggregating by Groups}

It is vital to look beyond national averages, as these disaggregated analyses of poverty reduction by region and ethnicity add very important information. Why?

Consider Nigeria, Benin, Zambia, and Niger. Each country reduced MPI significantly, and the average absolute rate of reduction was about the same - at 0.011 or 0.012 per year. However, in Nigeria, significant reductions occurred in only one region which houses $13 \%$ of the country's poor people; there was no significant change in the other regions. In contrast, in Zambia, there were changes in regions housing $67 \%$ percent of poor people; in Benin, $81 \%$ of poor people, and Niger had statistically significant changes in $100 \%$ of its subnational regions.

\section{TRACKING CHANGES ACROSS SUBNATIONAL REGIONS}

We track MPI changes over time for 338 subnational regions, reporting their MPI, $\mathrm{H}$ and $\mathrm{A}$, and the composition of their poverty and how it changed over time.

Eight countries - Bangladesh (2007-11), Bolivia, Gabon, Ghana, Malawi, Mozambique, Niger, and Rwanda - showed statistically significant reductions in each of their subnational regions, which is truly stellar progress.
Happily, in nine countries the poorest subnational area made the biggest strides in reducing multidimensional poverty. In Bangladesh (2007-2011), Bolivia, Colombia, Egypt, Kenya, Malawi, Mozambique, Namibia and Niger, the poorest region reduced poverty the most.

In total, 208 regions which are home to $78 \%$ of the poor showed statistically significant reductions in MPI.

\section{MIXED PROGRESS FOR DIFFERENT ETHNIC GROUPS}

In Benin, Ghana and Kenya, we compare changes over time across the main ethnic groups. All three countries had statistically significant reductions in MPI. But these gains were distributed very differently across ethnic groups.

Benin reduced MPI significantly for only two out of the eight main ethnic groups, and poverty reduction was practically zero among the poorest ethnic group, the Peulh. Figure 3 shows MPI levels in 2003 and annualized absolute change in MPI for the eight main ethnic groups in Benin. There is a clear upward trend. The poorer ethnic groups tend to reduce poverty less than the 'richer' groups. For example, the gap between the MPI of the Peulh and the Yoruba, the least poor group, increased from 0.320 to 0.365 points. This kind of increase in disparity across ethnic groups reflects an increase in horizontal inequality among the poor.

Ghana cut poverty among all ethnic groups, although the reduction was not statistically significant among the Guan. In contrast to Benin, here the poorer ethnic groups reduced MPI at least slightly more than the less poor groups.

In contrast, Kenya had an excellent performance. The MPI poorest group, the Somali, had the biggest (absolute) reduction in poverty, reducing poverty at a yearly rate of 4.6 percent, 1.1 percentage points faster than the national rate of 3.5 percent. The gap between this group and the top group, the Kikuyo, has reduced from 0.428 to 0.335 . Kenya's trend is pro-poor and equalizing, because the poorest ethnic groups are catching up.

Table 1: Relative change in $\mathrm{MPI}_{\mathrm{T}}$ and GNI per capita growth

\begin{tabular}{|c|c|c|c|c|c|}
\hline \multirow[b]{2}{*}{ Countries } & \multicolumn{3}{|c|}{ Multidimensional Poverty } & \multicolumn{2}{|c|}{ GNI per capita } \\
\hline & $\mathrm{MPI}_{\mathrm{T}}$ Year 1 & $\begin{array}{l}\text { Annualized absolute } \\
\text { change in } \mathrm{MPI}_{\mathrm{T}}\end{array}$ & $\begin{array}{l}\text { Annualized } \\
\text { relative change } \\
\text { in } \mathrm{MPI}_{\mathrm{T}}\end{array}$ & $\begin{array}{l}\text { GNI per capita in Year 1, } \\
\text { Atlas method } \\
\text { (current US\$) }\end{array}$ & $\begin{array}{l}\text { Average GNI per } \\
\text { capita growth } \\
\text { (annual \%) }\end{array}$ \\
\hline Bangladesh 2004-2007 & 0.364 & -0.020 & $-5.7 \%$ & 430 & $5.4 \%$ \\
\hline Bangladesh 2007-2011 & 0.306 & -0.015 & $-5.4 \%$ & 510 & $5.5 \%$ \\
\hline Bolivia 2003-2008 & 0.175 & -0.017 & $-12.6 \%$ & 900 & $2.5 \%$ \\
\hline Cambodia 2005-2010 & 0.299 & -0.017 & $-6.7 \%$ & 460 & $6.1 \%$ \\
\hline Cameroon 2004-2011 & 0.298 & -0.007 & $-2.6 \%$ & 800 & $0.8 \%$ \\
\hline Ethiopia 2000-2005 & 0.677 & -0.014 & $-2.2 \%$ & 120 & $3.6 \%$ \\
\hline Ethiopia 2005-2011 & 0.604 & -0.013 & $-2.3 \%$ & 160 & $8.2 \%$ \\
\hline Ghana 2003-2008 & 0.309 & -0.021 & $-8.1 \%$ & 320 & $4.8 \%$ \\
\hline India 1998/9-2005/6 & 0.304 & -0.007 & $-2.5 \%$ & 435 & $5.1 \%$ \\
\hline Nepal 2006-2011 & 0.350 & -0.027 & $-9.1 \%$ & 350 & $3.1 \%$ \\
\hline Rwanda 2005-2010 & 0.461 & -0.026 & $-6.4 \%$ & 260 & $5.6 \%$ \\
\hline Tanzania 2008-2010 & 0.371 & -0.018 & $-5.0 \%$ & 450 & $3.5 \%$ \\
\hline Uganda 2006-2011 & 0.420 & -0.015 & $-3.9 \%$ & 330 & $4.5 \%$ \\
\hline
\end{tabular}


POVERTY DYNAMICS IN RURAL AND URBAN AREAS

For each of the 34 countries studied, we present the levels and changes in MPI and its consistent indices by rural and urban areas. ${ }^{6}$ Poverty was higher in rural than urban areas in all of the countries in both of the periods. Twenty six countries had significant reductions in urban poverty; and 30 in rural areas.

Rural areas as a whole reduced multidimensional poverty faster than urban areas. On average, rural areas reduced the headcount ratio by 1.3 percentage points per year as compared to 1 percentage point per year for urban areas. The annualized average rural MPI reduction was 0.009, whereas the urban MPI reduction was 0.005 . Naturally rural-urban migration will also have affected these rates. Rural and urban areas both reduced sanitation deprivations most, and tended to have stronger reductions in living standard indicators. However, rural areas had faster rates of reduction in most indicators.

Across all countries the composition of poverty differed across urban and rural areas, with deprivations in electricity, water and flooring contributing more to MPI in rural areas, and deprivations in child mortality, malnutrition, and school attendance contributing relatively more to urban poverty.

\section{INEQUALITY AMONG THE POOR AND REGIONAL DISPARITIES}

We summarize inequalities using two measures: one reflecting inequality among the poor, and the second, disparity in MPI across subnational regions. The first can be used to detect 'pockets of poverty' in relatively less poor contexts; the second to show changes in horizontal inequality.

Large absolute and relative reductions in inequality among the poor took place in Cambodia, Rwanda, and the Dominican Republic.

Across the 31 countries for which we have subnational data, the largest absolute reduction in regional disparities occurred in Haiti, Nepal, Kenya and Zimbabwe, followed by Namibia, and Gabon. The largest relative reductions in disparity in MPI across regions occurred in the Dominican Republic, Egypt, Nepal and Peru. The only country for which sub-national disparity increased statistically significantly is India. That is, in India between 1998/9 and 2005/6, the poorest regions had a slower reduction in MPI; they were being left behind.

\section{POPULATION GROWTH AND POVERTY REDUCTION}

In order to eradicate poverty, the speed of reduction in the multidimensional headcount ratio $(\mathrm{H})$ has to outpace population growth. Of the 30 countries that reduced MPI significantly, when population growth is taken into account, only 20 countries reduced the number of poor people across the periods. In ten countries, population growth wiped out poverty reduction: in Benin, Cameroon, Ethiopia, Kenya, Malawi, Mozambique, Niger, Pakistan, Uganda and Zambia, the absolute number of poor people went up.

\section{MPI VS INCOME POVERTY}

Around half of the countries for which we have income data for a similar period reduced multidimensional poverty faster than income poverty; in the remaining countries, income poverty reduced faster.
Bolivia, Ghana, and Rwanda cut MPI poverty two to three times faster than income poverty. Nepal made stellar progress in both. Niger, Uganda, Cambodia, and Ethiopia had much stronger absolute and relative reductions in income poverty than in multidimensional poverty. In Nigeria and Zambia while MPI incidence reduced, income poverty increased.

If progress was only measured by reducing income poverty, Niger, Uganda, Cambodia, Nepal, Mozambique and Ethiopia would be considered the leaders in poverty reduction. The tremendous gains of Rwanda, Ghana, and Bolivia among others would have been invisible.

Fig. 4: Poverty reduction among ethnic groups in Benin

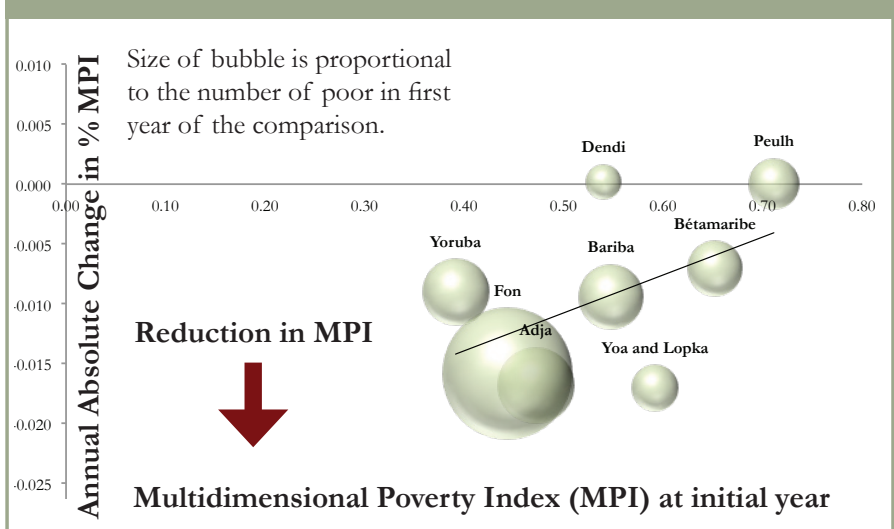

Fig. 5: Poverty reduction among ethnic groups in Kenya

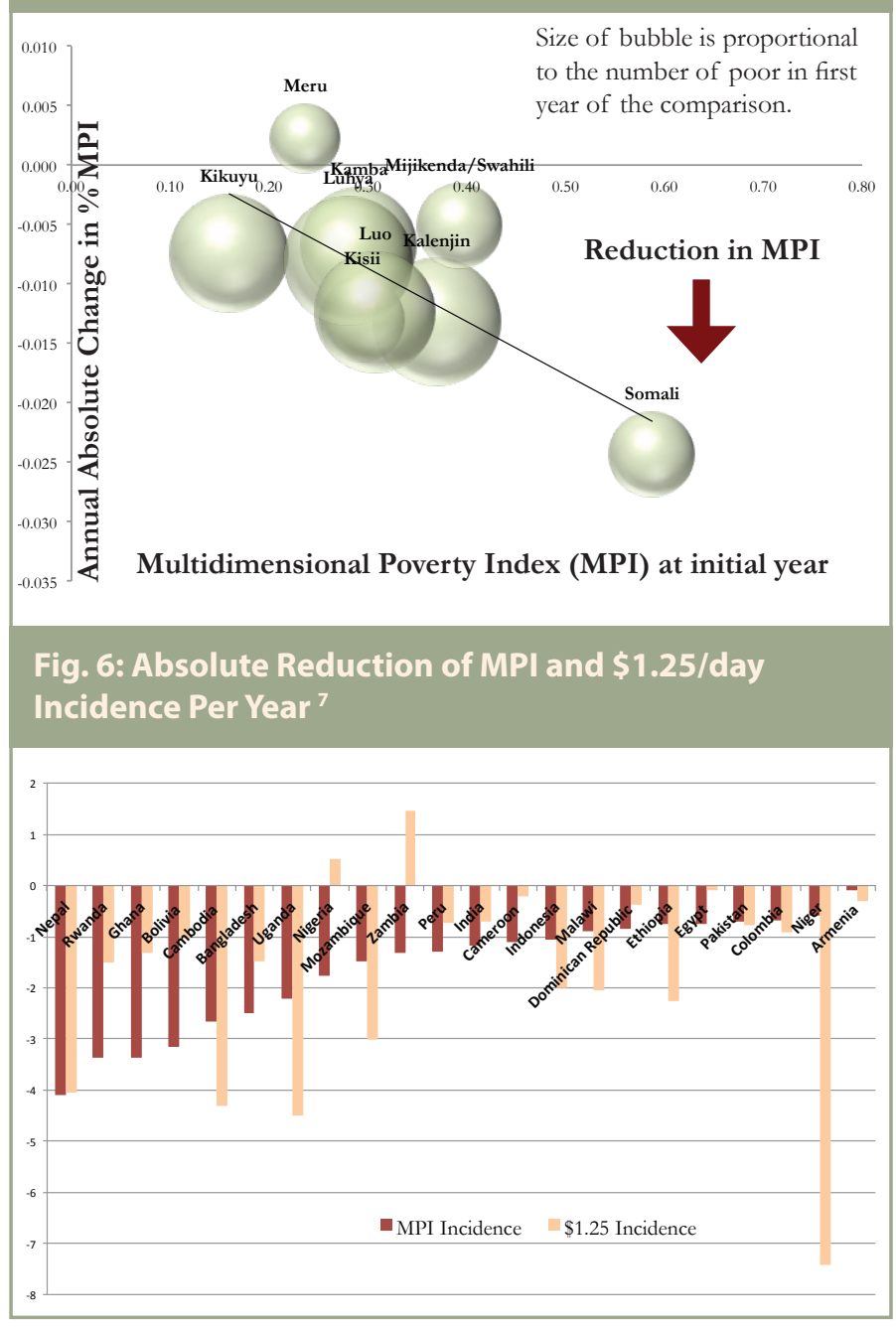




\section{GROWTH IN GNI PER CAPITA AND POVERTY REDUCTION}

The level of success in translating the gains of growth into poverty reduction varies across countries, and also sometimes across periods. For instance, in the periods under analysis, Bangladesh and India registered similar rates of growth in GNI per capita, but Bangladesh reduced MPI more than twice as fast as India. On the other hand, although India has grown six times faster than Cameroon, the latter reduced MPI as fast as India. Finally, although the average growth rate in Ethiopia more than doubled between the period 2000-2005 and 2005-2008, the annualized relative change in the MPI remained practically the same.

\section{DESTITUTION - DID THINGS CHANGE FOR THE POOREST OF THE POOR?}

In addition to studying trends in multidimensional poverty, we study trends in destitution for the same countries and periods. The destitution indicators are more extreme: for example, severe malnutrition instead of malnutrition; losing two children; having all primary school-aged children out of school; not having anyone with at least a year of schooling in the household; practising open defecation; and so on. Only for electricity and flooring are the indicators unchanged. A person is destitute if he or she is deprived in at least a third of the weighted destitution indicators (Alkire, Conconi and Seth 2014).

The good news is that 28 of our 34 countries reduced destitution significantly, and in nearly all of them, destitution rates fell (in relative terms) faster than multidimensional poverty rates.

What's noticeable again is that the countries doing best at tackling destitution are mostly LICs and LDCs; the largest absolute reduction in the destitution MPI was seen in Ethiopia, followed by Niger, Ghana, Bolivia, Rwanda, Tanzania, Nepal, Haiti, Bangladesh and Zambia - all of them LICS or LDCs except Ghana and Bolivia.

Between 2000 and 2011, Ethiopia reduced the percentage of the population who were destitute by a massive 30 percentage points, and reduced intensity among the destitute by fully 10 percentage points. That is, the average poor person in 2011 was deprived in nearly two standard of living indicators less than the average poor person had been in 2000. During the first five years, reduction sped forward at 3.3 percentage points each year, with significant reductions in all indicators, and the strongest gains in water, sanitation, and educational variables. From 2005 to 2011 progress slowed slightly, but the reduction was still impressive at 2.2 percentage points of the population annually. Niger's rate of destitution-MPI reduction matched that of Ethiopia 2005-2011.

In the large majority of the countries, destitution is more prevalent in rural areas. Fortunately, it is also in those areas that most countries have made more important progress in absolute terms. Rural reductions in destitution were statistically significant in 27 countries, whereas urban reductions were significant in only 20 countries. In terms of indicators, the majority of the countries registered significant improvements in sanitation and child mortality, suggesting that health and sanitation policies are playing an important role in improving the lives of the poorest of the poor.
Table 2: Changes in Multidimensional Poverty \& Destitution

\begin{tabular}{|c|c|c|c|c|c|}
\hline \multirow[b]{2}{*}{ Country and Period } & \multicolumn{2}{|c|}{$\begin{array}{c}\text { MPI }_{\mathrm{T}} \\
\text { Values }\end{array}$} & \multicolumn{2}{|c|}{$\begin{array}{c}\text { Annualized Change } \\
\text { in } \mathrm{MPI}_{\mathrm{T}}\end{array}$} & \multirow{2}{*}{$\begin{array}{l}\text { Stat. } \\
\text { Sig. }\end{array}$} \\
\hline & Year 1 & Year 2 & Absolute & Relative & \\
\hline Armenia 2005-2010 & .003 & .001 & 0.000 & $-17.7 \%$ & ** \\
\hline Bangladesh 2004-2007 & .364 & .306 & -0.020 & $-5.7 \%$ & $* * *$ \\
\hline Bangladesh 2007-2011 & .306 & .245 & -0.015 & $-5.4 \%$ & $* * *$ \\
\hline Benin 2001-2006 & .474 & .414 & -0.012 & $-2.7 \%$ & $* * *$ \\
\hline Bolivia 2003-2008 & .175 & .089 & -0.017 & $-12.6 \%$ & $* * *$ \\
\hline Cambodia 2005-2010 & .299 & .212 & -0.017 & $-6.7 \%$ & $* * *$ \\
\hline Cameroon 2004-2011 & .298 & .248 & -0.007 & $-2.6 \%$ & $* * *$ \\
\hline Colombia 2005-2010 & .039 & .023 & -0.003 & $-9.8 \%$ & $* * *$ \\
\hline Dominican Rep. 2002-2007 & .040 & .020 & -0.004 & $-13.0 \%$ & $* * *$ \\
\hline Egypt 2005-2008 & .034 & .024 & -0.003 & $-10.7 \%$ & $* * *$ \\
\hline Ethiopia 2000-2005 & .677 & .604 & -0.014 & $-2.2 \%$ & $* * *$ \\
\hline Ethiopia 2005-2011 & .604 & .526 & -0.013 & $-2.3 \%$ & $* * *$ \\
\hline Gabon 2000-2012 & .161 & .075 & -0.007 & $-6.1 \%$ & $* * *$ \\
\hline Ghana 2003-2008 & .309 & .202 & -0.021 & $-8.1 \%$ & $* * *$ \\
\hline Guyana 2005-2009 & .050 & .041 & -0.002 & $-4.5 \%$ & * \\
\hline Haiti 2005/6-2012 & .335 & .248 & -0.013 & $-4.5 \%$ & $* * *$ \\
\hline India 1998/9-2005/6 & .304 & .254 & -0.007 & $-2.5 \%$ & $* * *$ \\
\hline Indonesia 2007-2012 & .095 & .066 & -0.006 & $-7.0 \%$ & $* * *$ \\
\hline Jordan 2007-2009 & .013 & .011 & -0.001 & $-8.9 \%$ & \\
\hline Kenya 2003-2008/9 & .296 & .244 & -0.009 & $-3.5 \%$ & $* * *$ \\
\hline Lesotho 2004-2009 & .238 & .190 & -0.010 & $-4.4 \%$ & $* * *$ \\
\hline Madagascar 2004-2008/9 & .374 & .414 & 0.009 & $2.3 \%$ & $* * *$ \\
\hline Malawi 2004-2010 & .381 & .334 & -0.008 & $-2.2 \%$ & $* * *$ \\
\hline Mozambique 2003-2011 & .505 & .393 & -0.014 & $-3.1 \%$ & $* * *$ \\
\hline Namibia 2000-2007 & .194 & .154 & -0.006 & $-3.2 \%$ & $* * *$ \\
\hline Nepal 2006-2011 & .350 & .217 & -0.027 & $-9.1 \%$ & $* * *$ \\
\hline Niger 2006-2012 & .696 & .621 & -0.012 & $-1.9 \%$ & $* * *$ \\
\hline Nigeria 2003-2008 & .368 & .313 & -0.011 & $-3.2 \%$ & $* * *$ \\
\hline Pakistan 2006/7-2012/13 & .264 & .235 & -0.005 & $-2.0 \%$ & $* * *$ \\
\hline Peru 2005-2008 & .085 & .066 & -0.006 & $-8.0 \%$ & * \\
\hline Peru 2008-2012 & .066 & .043 & -0.006 & $-10.3 \%$ & $* * *$ \\
\hline Rwanda 2005-2010 & .461 & .330 & -0.026 & $-6.4 \%$ & $* * *$ \\
\hline Senegal 2005-2010/11 & .440 & .423 & -0.003 & $-0.7 \%$ & \\
\hline Tanzania 2008-2010 & .371 & .335 & -0.018 & $-5.0 \%$ & $* * *$ \\
\hline Uganda 2006-2011 & .420 & .343 & -0.015 & $-3.9 \%$ & $* * *$ \\
\hline Zambia 2001/2-2007 & .397 & .332 & -0.012 & $-3.2 \%$ & $* * *$ \\
\hline Zimbabwe 2006-2010/11 & .180 & .145 & -0.008 & $-4.7 \%$ & $* * *$ \\
\hline
\end{tabular}

Note: ${ }^{* * *}$ statistically significant at $\mathrm{a}=0.01,{ }^{* *}$ statistically significant 


\begin{tabular}{|c|c|c|c|c|c|c|c|c|c|c|c|c|c|}
\hline \multicolumn{2}{|c|}{$\begin{array}{c}\text { Annualized Change } \\
\text { in } \mathrm{H}\end{array}$} & \multirow{2}{*}{$\begin{array}{l}\text { Stat. } \\
\text { Sig. }\end{array}$} & \multicolumn{2}{|c|}{ Annualized Change in A } & \multirow{2}{*}{$\begin{array}{l}\text { Stat. } \\
\text { Sig. }\end{array}$} & \multicolumn{2}{|c|}{$\begin{array}{l}\text { Destitution } \mathrm{MPI}_{\mathrm{T}} \\
\quad \text { Values }\end{array}$} & \multicolumn{2}{|c|}{$\begin{array}{l}\text { Annualized Change in } \\
\text { Destitution } \mathrm{MPI}_{T}\end{array}$} & \multirow{2}{*}{$\begin{array}{l}\text { Stat. } \\
\text { Sig. }\end{array}$} & \multicolumn{2}{|c|}{$\begin{array}{c}\text { Annualized Change in } \\
\text { Destitute } H\end{array}$} & \multirow{2}{*}{$\begin{array}{l}\text { Stat. } \\
\text { Sig. }\end{array}$} \\
\hline Absolute & Relative & & Absolute & Relative & & Year 1 & Year 2 & Absolute & Relative & & Absolute & Relative & \\
\hline-0.1 & $-12.4 \%$ & $* *$ & -0.1 & $-0.1 \%$ & & .000 & 0.000 & 0.000 & $62.3 \%$ & & 0.0 & $57.4 \%$ & \\
\hline-2.7 & $-4.2 \%$ & $* * *$ & -0.8 & $-1.6 \%$ & $* * *$ & .124 & 0.097 & -0.009 & $-7.9 \%$ & $* * *$ & -2.0 & $-7.3 \%$ & $* * *$ \\
\hline-2.4 & $-4.2 \%$ & $* * *$ & -0.6 & $-1.2 \%$ & $* * *$ & .097 & 0.071 & -0.007 & $-7.6 \%$ & $* * *$ & -1.4 & $-6.8 \%$ & $* * *$ \\
\hline-1.4 & $-1.8 \%$ & $* * *$ & -0.5 & $-0.9 \%$ & $* * *$ & .236 & 0.194 & -0.008 & $-3.8 \%$ & $* * *$ & -1.7 & $-3.8 \%$ & *** \\
\hline-3.2 & $-10.8 \%$ & $* * *$ & -0.9 & $-2.0 \%$ & $* * *$ & .084 & 0.023 & -0.012 & $-22.6 \%$ & $* * *$ & -2.8 & $-21.4 \%$ & *** \\
\hline-2.7 & $-5.0 \%$ & $* * *$ & -0.9 & $-1.8 \%$ & $* * *$ & .094 & 0.057 & -0.007 & $-9.3 \%$ & $* * *$ & -1.6 & $-8.6 \%$ & $* * *$ \\
\hline-1.1 & $-2.2 \%$ & $* * *$ & -0.2 & $-0.4 \%$ & & .115 & 0.095 & -0.003 & $-2.7 \%$ & $* *$ & -0.6 & $-2.5 \%$ & $* * *$ \\
\hline-0.7 & $-8.9 \%$ & $* * *$ & -0.4 & $-0.9 \%$ & $* * *$ & .004 & 0.002 & 0.000 & $-13.1 \%$ & $* * *$ & -0.1 & $-12.8 \%$ & $* * *$ \\
\hline-0.8 & $-11.5 \%$ & $* * *$ & -0.7 & $-1.8 \%$ & $* * *$ & .007 & 0.002 & -0.001 & $-19.7 \%$ & $* * *$ & -0.2 & $-18.7 \%$ & $* * *$ \\
\hline-0.8 & $-10.2 \%$ & $* * *$ & -0.2 & $-0.5 \%$ & & .005 & 0.004 & 0.000 & $-5.6 \%$ & & -0.1 & $-5.1 \%$ & \\
\hline-0.7 & $-0.8 \%$ & $* * *$ & -1.0 & $-1.4 \%$ & $* * *$ & .471 & 0.339 & -0.026 & $-6.4 \%$ & $* * *$ & -3.3 & $-4.4 \%$ & $* * *$ \\
\hline-0.8 & $-0.9 \%$ & $* * *$ & -0.9 & $-1.4 \%$ & $* * *$ & .339 & 0.248 & -0.015 & $-5.1 \%$ & $* * *$ & -2.2 & $-3.7 \%$ & $* * *$ \\
\hline-1.5 & $-5.7 \%$ & $* * *$ & -0.2 & $-0.4 \%$ & $* * *$ & .040 & 0.013 & -0.002 & $-8.7 \%$ & $* * *$ & -0.5 & $-8.5 \%$ & $* * *$ \\
\hline-3.4 & $-6.5 \%$ & $* * *$ & -0.9 & $-1.7 \%$ & $* * *$ & .128 & 0.059 & -0.014 & $-14.2 \%$ & $* * *$ & -2.9 & $-13.2 \%$ & $* * *$ \\
\hline-0.5 & $-4.4 \%$ & * & 0.0 & $-0.1 \%$ & & .021 & 0.008 & -0.003 & $-21.8 \%$ & *** & -0.9 & $-22.1 \%$ & $* * *$ \\
\hline-1.7 & $-3.1 \%$ & $* * *$ & -0.8 & $-1.5 \%$ & $* * *$ & .138 & 0.078 & -0.009 & $-8.5 \%$ & $* * *$ & -1.8 & $-7.5 \%$ & $* * *$ \\
\hline-1.2 & $-2.2 \%$ & $* * *$ & -0.2 & $-0.3 \%$ & $* * *$ & .142 & 0.111 & -0.004 & $-3.4 \%$ & $* * *$ & -0.9 & $-3.1 \%$ & *** \\
\hline-1.1 & $-5.7 \%$ & $* * *$ & -0.6 & $-1.3 \%$ & $* * *$ & .027 & 0.017 & -0.002 & $-8.5 \%$ & $* * *$ & -0.4 & $-7.5 \%$ & $* * *$ \\
\hline-0.3 & $-7.8 \%$ & & -0.4 & $-1.2 \%$ & & .000 & 0.001 & 0.000 & $11.0 \%$ & & 0.0 & $14.0 \%$ & \\
\hline-1.6 & $-2.9 \%$ & $* * *$ & -0.3 & $-0.6 \%$ & * & .105 & 0.076 & -0.005 & $-5.7 \%$ & $* * *$ & -1.1 & $-5.0 \%$ & $* * *$ \\
\hline-1.7 & $-3.7 \%$ & $* * *$ & -0.4 & $-0.8 \%$ & $* * *$ & .085 & 0.056 & -0.006 & $-7.8 \%$ & *** & -1.4 & $-7.5 \%$ & *** \\
\hline 1.4 & $2.0 \%$ & $* * *$ & 0.2 & $0.3 \%$ & & .136 & 0.130 & -0.001 & $-1.1 \%$ & & 0.0 & $-0.2 \%$ & \\
\hline-0.9 & $-1.3 \%$ & $* * *$ & -0.4 & $-0.9 \%$ & $* * *$ & .123 & 0.094 & -0.005 & $-4.5 \%$ & $* * *$ & -1.1 & $-3.9 \%$ & $* * *$ \\
\hline-1.5 & $-1.9 \%$ & $* * *$ & -0.7 & $-1.2 \%$ & $* * *$ & .234 & 0.169 & -0.008 & $-4.0 \%$ & $* * *$ & -1.4 & $-3.2 \%$ & $* * *$ \\
\hline-1.1 & $-2.9 \%$ & $* * *$ & -0.2 & $-0.4 \%$ & * & .074 & 0.049 & -0.004 & $-5.8 \%$ & $* * *$ & -0.8 & $-5.3 \%$ & $* * *$ \\
\hline-4.1 & $-7.4 \%$ & $* * *$ & -1.0 & $-1.9 \%$ & $* * *$ & .141 & 0.095 & -0.009 & $-7.7 \%$ & $* * *$ & -1.9 & $-6.7 \%$ & $* * *$ \\
\hline-0.6 & $-0.6 \%$ & $* * *$ & -0.9 & $-1.3 \%$ & $* * *$ & .473 & 0.378 & -0.016 & $-3.7 \%$ & *** & -1.5 & $-2.0 \%$ & $* * *$ \\
\hline-1.8 & $-3.0 \%$ & $* * *$ & -0.1 & $-0.2 \%$ & & .226 & 0.185 & -0.008 & $-3.9 \%$ & $* * *$ & -1.7 & $-4.1 \%$ & $* * *$ \\
\hline-0.7 & $-1.5 \%$ & $* * *$ & -0.3 & $-0.5 \%$ & ** & .110 & 0.102 & -0.001 & $-1.2 \%$ & & -0.2 & $-0.7 \%$ & \\
\hline-1.3 & $-6.9 \%$ & * & -0.5 & $-1.1 \%$ & $* *$ & .019 & 0.013 & -0.002 & $-13.5 \%$ & $* *$ & -0.6 & $-13.3 \%$ & $* *$ \\
\hline-1.3 & $-9.6 \%$ & $* * *$ & -0.3 & $-0.7 \%$ & $* *$ & .013 & 0.008 & -0.001 & $-12.1 \%$ & $* * *$ & -0.3 & $-11.7 \%$ & $* * *$ \\
\hline-3.4 & $-4.4 \%$ & $* * *$ & -1.1 & $-2.1 \%$ & $* * *$ & .151 & 0.096 & -0.011 & $-8.7 \%$ & $* * *$ & -2.2 & $-7.1 \%$ & $* * *$ \\
\hline-0.1 & $-0.1 \%$ & & -0.4 & $-0.6 \%$ & * & .205 & 0.183 & -0.004 & $-2.0 \%$ & * & -0.9 & $-2.2 \%$ & $* *$ \\
\hline-2.3 & $-3.5 \%$ & $* * *$ & -0.9 & $-1.6 \%$ & $* * *$ & .130 & 0.108 & -0.011 & $-8.7 \%$ & $* * *$ & -1.8 & $-7.5 \%$ & $* * *$ \\
\hline-2.2 & $-3.0 \%$ & $* * *$ & -0.5 & $-0.9 \%$ & $* * *$ & .142 & 0.112 & -0.006 & $-4.6 \%$ & $* * *$ & -1.1 & $-3.6 \%$ & $* * *$ \\
\hline-1.3 & $-1.9 \%$ & $* * *$ & -0.7 & $-1.3 \%$ & $* * *$ & .165 & 0.119 & -0.008 & $-5.8 \%$ & $* * *$ & -1.6 & $-4.9 \%$ & $* * *$ \\
\hline-1.4 & $-3.7 \%$ & $* * * *$ & -0.5 & $-1.0 \%$ & $* * *$ & .069 & 0.044 & -0.006 & $-9.5 \%$ & $* * *$ & -1.4 & $-9.2 \%$ & $* * *$ \\
\hline
\end{tabular}




\section{CONCLUSION}

This briefing has shown how 34 countries have fared in reducing multidimensional poverty. We have scrutinised their experiences by speed and by indicator, by subnational region, by ethnic group, by rural-urban area, and by inequality among the poor. We've compared their achievements in multidimensional poverty reduction with those in reducing a complementary income-based measure of poverty, and observed varying relationships with economic growth.

Fundamentally, however, we measure poverty so we can try to eradicate it. A 'how' analysis like this could be usefully complemented by many 'why' analyses, with country-specific details on policy and context. These combined analyses - the measurement and analysis of successful poverty reduction - can be used to inform citizens, target resources, design policies and institutions, advertise strategies of success, monitor progress, and otherwise lend more energy and insight to poverty reduction. Well-communicated poverty measures can also draw other actors - from poor people and communities to the private sector, philanthropists and volunteers - to join in this work and increase its chances of success.

\section{NOTES}

All population estimates are taken from United Nations, Department of Economic and Social Affairs, Population Division (2013). World Population Prospects: The 2012 Revision, CD-ROM Edition.

1. These are the countries for which there was a recent MPI estimation and comparable Demographic and Health Survey (DHS) datasets for analysis across time; 29 countries have all 10 indicators; 4 countries lack nutrition and Egypt lacks cooking fuel.

2. To construct definitive comparisons of MPI over time, we restrict comparisons to information that was exactly the same in both periods. Thus the MPI ${ }_{\mathrm{T}}$ always differs slightly from MPI published values except in Armenia 2010, Benin 2001, Bolivia 2003 and 2008, Cambodia 2010, Cameroon 2011, Colombia 2005, Egypt 2008, Ethiopia 2000, Ghana 2003, Guyana 2005, Haiti 2012, India 1998/99, Indonesia 2007 and 2012, Kenya 2003, Malawi 2004 and 2010, Namibia 2000, Nepal 2006 and 2011, Nigeria 2003, Pakistan 2006/7, Peru 2005, 2008 and 2012, Tanzania 2008, Zambia 2001, and Zimbabwe 2011.. For details of each adjustment see Alkire, Conconi and Seth 2014 and Alkire Roche and Vaz 2013; for India in particular see Alkire and Seth 2013.

3. Our cross-national comparisons of changes in the MPI are constrained by differences in precise variable definitions (though they are well harmonized for the same country across time), and by differences in the years and periods between surveys.

Oxford Poverty \& Human Development Initiative (OPHI)

Oxford Department of International Development (ODID)

Queen Elizabeth House (QEH)

University of Oxford, Mansfield Road

Oxford OX1 3TB UK

Telephone: +44 (0)1865 271915

Email: ophi@qeh.ox.ac.uk

Website: $\quad$ www.ophi.org.uk

OPHI gratefully acknowledges support from research councils, non-governmental and governmental organisations, and private benefactors. For a list of our funders and donors, please visit our website: www.ophi.org.uk.
Rural-urban designations may use different definitions, and these and subnational group definitions may or may not reflect demographic shifts precisely, hence we do not yet generalize findings on migration and other shifts that affect poverty trends. When constructing population-weighted aggregates, we use the population figures from the year of the survey (although headline findings are cross-checked using different population aggregations).

4. All statistical significance is evaluated at the level of $\alpha=0.05$. Ethiopia, Peru and Bangladesh had comparisons for two periods. Guyana had statistically significant reductions but only at $\alpha=0.10$, as did Peru 2005-2008. 29 countries' changes were significant even at $\alpha=0.01$. Madagascar had a statistically significant increase in MPI at $\alpha=0.01$.

5. Indonesia reduced all indicators for which there is information, which excludes nutrition.

6. The DHS surveys use the national census definitions to identify rural and urban clusters, then update the household listings to reflect major population shifts.

7. The graph only includes countries where the reduction in MPI headcount was statistically significant and for which we have data on income poverty.

8. If a country has two periods, we observe if it reduced an indicator in at least one period.

\section{REFERENCES}

Alkire, S., A. Conconi and S. Seth (2014): 'Measuring Destitution in Developing Countries: An Ordinal Approach for Identifying Linked Subsets of the Multidimensionally Poor', OPHI Research in Progress.

Alkire, S. and Foster, J.E. (2011): "Counting and Multidimensional Poverty Measurement”, Journal of Public Economics, 95(7): 476-487.

Alkire, S. and Roche, J.M. (2013): "How Successful are Countries in Reducing Multidimensional Poverty? Insights from InterTemporal Analysis in 22 Countries”, OPHI Mimeo.

Alkire, S, J.M. Roche, and A. Vaz (2014): 'Multidimensional Poverty Dynamics: Methodology and Results for 34 Countries'. OPHI Research in Progress.

Sen, A.K. (2009): The Idea of Justice, Penguin.

Seth S. and Alkire, S. (2014): "Measuring and Decomposing Inequality among the Multidimensionally Poor Using Ordinal Data: A Counting Approach", OPHI Working Paper No 68, Oxford Poverty and Human Development Initiative, University of Oxford.

UNDP (2010): "What will it take to achieve the Millennium Development Goals? An International assessment" New York: UNDP.

World Bank (2014). World Development Indicators.

Washington DC: World Bank. 